\title{
O texto literário como veículo de diálogo intercultural no ensino/aprendizagem da língua portuguesa
}

\section{The literary text as intercultural dialogue vehicle in the teaching/learning Portuguese}

\author{
Mafalda Moço \\ InOCÊnCIA LuCiano dos Santos Mata *
}

\begin{abstract}
Resumo: Num mundo em que a diferença se tornou conflitiva, por várias razões, é imperativo apostar numa educação intercultural que fomente não apenas o contacto mas o diálogo com o outro. Neste artigo, pretendemos refletir sobre o modo como o diálogo entre culturas pode ser implementado no contexto do ensino / aprendizagem da língua portuguesa, a partir do texto literário. Baseámo-nos nas propostas teóricas de Abdallah-Pretceille (1996), relativamente à pedagogia intercultural, de Carlo (1998), para a definição de intercultural, e de Esteves (1991), para a reflexão sobre o papel do texto literário na aula de português.
\end{abstract}

Palavras-chave: texto literário, pedagogia intercultural, consciência intercultural, diálogo intercultural.

Abstract: In a world where the difference became conflictive, for several reasons, it is urgent to invest in intercultural education that fosters not only the contact but the dialogue with the other. In this article, we intend to think about how the dialogue between cultures can be fostered in the context of teaching / learning Portuguese, from the literary text. The article is based on theoretical proposals of Abdallah-Pretceille (1996), regarding the intercultural pedagogy, of Carlo (1998), to define intercultural, and of Esteves (1991), to think about the importance of the literary text in a Portuguese class. Keywords: literary text, intercultural pedagogy, intercultural awareness, intercultural dialogue.

* Faculdade de Letras da Universidade de Lisboa.

${ }^{* *}$ Professora da Universidade de Lisboa. 
Uma educação para a diferença: um imperativo das sociedades contemporâneas

A configuração do mundo em que vivemos coloca-nos em contacto com duas realidades concetualizadas em categorias como a multiculturalidade / sociedade multicultural e interculturalidade.

Por sociedade multicultural entende-se, com base na definição apresentada pelo Conselho da Europa em Education Pack (2004), uma sociedade em que a diferença não é vista como uma mais-valia, mas é encarada como a principal justificação para as mais frequentes formas de discriminação. No entanto, pretende-se que a sociedade multicultural se torne, progressivamente, numa sociedade em que as diferentes culturas possam dialogar, em que diferentes grupos, que partilham o mesmo território, possam manter relações abertas de interação, troca e reconhecimento mútuo dos seus próprios valores e formas de vida. Neste sentido, é fundamental que a Educação fomente o contacto com o outro contribuindo para que, gradualmente, a nossa sociedade se transforme numa sociedade intercultural.

A fim de implementar o diálogo entre as diferentes culturas, o indivíduo, enquanto ser social, terá de ser educado, transformado, num ser intercultural, um ser capaz de estabelecer pontes de diálogo com o outro, que tem uma cultura diferente da sua, que é, simplesmente diferente. Segundo Maddalena del Carlo (1998: 41) o termo intercultural diz respeito à interação e troca de valores, modos de vida e representações simbólicas que pressupõe a eliminação das barreiras existentes, numa atitude solidária, recíproca e verdadeira. Esta interação é facilitada se o indivíduo desenvolver uma identidade dinâmica e plural (Abdallah-Pretceille, 1996).

Um ensino que se baseie numa aproximação intercultural pretende então, não apenas o reconhecimento da existência de diferentes culturas, mas também a promoção da interação, da troca, da eliminação de barreiras, da reciprocidade e de uma verdadeira solidariedade entre culturas. $O$ facto de a língua portuguesa ser uma língua pluricultural, isto é, uma língua que se tornou veículo de várias culturas, favorece uma educação intercultural, quer no ensino / aprendizagem do português como língua materna (PLM) quer como do português como língua não materna (PLNM), nomeadamente através do texto literário em língua portuguesa, também ele de caráter pluricultural. 
A dimensão plural da língua portuguesa e o caráter pluricultural do texto literário, podem ser potenciados de forma a incentivar os alunos a contactar com o outro, com diferentes visões do mundo, favorecendo uma reflexão sobre a identidade nacional, cultural e literária do seu país a partir do diálogo com uma identidade diferente, que imana do texto. Os textos literários e o uso estético que apresentam da língua são um importante estímulo ao diálogo intercultural, uma vez que permitem a construção de pontes entre universos distintos, a partir de um elemento comum: a língua portuguesa.

No entanto, atualmente, são várias as vozes que defendem que o estudo do texto literário impede uma boa aprendizagem da língua, argumentando que a forma como a língua é usada trabalha a rutura e a diferença e que afasta o aluno das necessidades de aprendizagem exigidas pelo mundo atual.

No caso do ensino / aprendizagem de PLNM, o texto literário deve ser uma alternativa a, outrora únicos documentos autênticos, concebidos sem fins pedagógicos e que refletem o uso real da língua, no contexto de uma abordagem comunicativa. No entanto, privilegiando este tipo de materiais, sociais, autênticos, abre-se "de novo a porta ao texto literário, considerado funcionalmente equivalente a outros registos de língua", como destaca José Manuel Esteves (1991: 143). O autor refere que o texto literário é, à semelhança de qualquer outro material, um núcleo potencial de múltiplas e diversas atividades comunicativas, dependentes da capacidade do ensinante em ir ao encontro das necessidades do seu público aprendente. Para além disso, o autor sublinha ainda que os defensores da ideia de que o texto literário não tem lugar no contexto do ensino / aprendizagem de uma língua estrangeira não consideram a abrangência da designação de "documento autêntico". Esta designação comporta todos os documentos que coloquem em evidência as potencialidades da língua e o texto literário encaixa-se nesta categoria: não foi publicado com fins pedagógicos, apesar de poder ser usado com essa finalidade e espelha uma modalidade do uso da língua. $O$ texto literário tem a capacidade de aproximar o aprendente da cultura da língua-alvo, nas suas diferentes utilizações. Aprender uma língua pressupõe também conhecer outras formas de ser, de sentir e de encarar o mundo, dá que defenda que o texto literário é um dos materiais didáticos (a partir do nível B2) que permite potenciar o conhecimento do outro e de si próprio, já que composta de diferentes visões do mundo, estimula múltiplas interpretações e fomenta o diálogo intercultural. 
No que diz respeito ao ensino / aprendizagem de PLM, o texto literário em língua portuguesa possibilita, por sua vez, o despertar da consciência intercultural do aluno, permitindo-Ihe o contacto com um texto escrito na mesma língua, mas com características diferentes, auxiliando-o a dominar a insegurança provocada pelo desconhecido e a generalizar as experiências de contacto com uma outra cultura, sem ceder à tentação de criar estereótipos.

A construção da nossa identidade, enquanto seres humanos, é feita através da interação com os outros, os sentidos dos outros, com o seu reconhecimento (Carlo, 1998). Num mundo globalizado, multicultural, plural - pluralidade que não tem qualquer relação com a diversidade exótica, mas, antes, com uma realidade marcada pelo crescimento de fluxos, de pessoas e ideias - é fundamental promover o diálogo com o outro e não apenas a coexistência com ele. Este diálogo com o outro é um diálogo intercultural na medida em que estabelece uma comunicação com a diferença já que o que se propõe é o acolhimento do outro e a transformação de ambos com esse encontro (Farmhouse, 2008). A identidade de um indivíduo é, mais do que um produto, uma construção constante, decorrente do diálogo, da interação e do contacto com o outro, com a diferença.

Se o texto literário é, como já foi referido, um lugar de contacto com a mundividência de determinada cultura, que comporta diferentes visões do mundo, talvez possa auxiliar na construção da identidade do indivíduo. Assumindo que o indivíduo se sente enclausurado em si próprio por considerar que a sua identidade é lacunar, ou seja, por considerar que lhe falta algo que o diminui perante o outro e que o impede de encarar o contacto com ele como uma troca, uma partilha dinâmica e construtiva a nível pessoal e social, o texto literário poderá constituir-se como lugar que permite o preenchimento dessa perceção de falta. Um exemplo que nos parece ilustrativo do que pretendemos demonstrar é o seguinte: considere-se um aprendente que não se sente "confortável" na sua relação com a natureza, no contexto da cultura da comunidade em que se insere e que, por essa razão, sente que a sua identidade é, de alguma forma, desajustada. Este aprendente está inserido num processo de ensino / aprendizagem de PLM ou PLNM e, neste contexto, contacta com um texto literário em língua portuguesa, um texto como $O$ último voo do flamingo de Mia Couto, que nos apresenta uma relação muito especial com a natureza que caracteriza muitos dos povos africanos. Este aprendente pode sentir-se próximo dessa forma de se relacionar com a natureza e pode adotá-la para si, pode passar a relacionar-se 
com a natureza daquele modo, sentindo que pertence, naquele aspeto da sua identidade, a uma outra cultura.

Este sentimento, esta "revelação" de que a outra cultura atribui à natureza um valor que preenche a lacuna identitária que o aprendente sentia, permite que este não se sinta excluído e que se identifique, naquele aspeto em particular, com outra cultura. Ao dialogar, ao interagir com um texto literário em língua portuguesa, do qual emerge uma outra cultura, o aprendente sentiu-se próximo dela, sentiu que poderia "adotar" aquele modo de se relacionar com a natureza, continuando o processo de construção da sua identidade, preenchendo o vazio que sentia. Este processo pode ser potenciado pela adoção de uma abordagem e pedagogia interculturais, no processo de ensino / aprendizagem quer de PLM quer de PLNM, na qual os alunos / aprendentes podem ser convidados a trabaIhar com textos em português mas não exclusivamente portugueses, dos quais transpira uma outra cultura, um outro modo de encarar o mundo, e a estabelecer uma ponte de diálogo entre a sua cultura e a que o texto transmite.

Toda esta reflexão nos conduz, na nossa perspetiva, à conclusão de que o texto literário em língua portuguesa permite ao aluno / aprendente o diálogo com o outro bem como o desenvolvimento da capacidade não só de reconhecer e compreender a diversidade mas de se sentir parte integrante da mesma, composta por si e pelo outro e enriquecida pelo diálogo entre ambos.

O facto de, como salienta Teresa Borges (2001), a leitura de um texto provocar sempre emoção, atribui ao ato de ler a capacidade de invadir a intimidade do indivíduo, podendo interferir na construção da sua identidade. Como escreve Amin Maalouf (1998), a identidade é composta, não por uma, mas por várias pertenças, isto é, por vários elementos que nos fazem pertencer a uma religião, a uma ou mais nacionalidades, a um grupo étnico ou linguístico, a um grupo de amigos etc. Como salienta o autor, "a identidade não se compartimenta, não se reparte em metades nem em terços, nem se delimita em margens fechadas" (Maalouf, 1998: 10), acrescentando que, mesmo admitindo que existe uma hierarquia entre os elementos constituintes de uma identidade, esta hierarquia não é imutável, "muda com o tempo e modifica profundamente os comportamentos" (idem, p. 22). No entanto, para que a leitura possa interferir na construção da identidade do aprendente, este, enquanto leitor, tem de se sentir motivado a encarar o texto não como um produto acabado, mas como algo dinâmico, com o qual ele pode interagir. A interação facilita a compreensão na medida em que 
exige questionamento, reflexão, crítica, expectativa, tornando o leitor um sujeito ativo, engajado e motivado a compreender o texto, disponível para aceder aos seus múltiplos sentidos. Ao ler um texto literário, o leitor está a contactar com uma nova visão do mundo, com a qual se pode identificar, por poder ir ao encontro da sua, completando-a ou questionando-a. Essa complementaridade, ou esse questionamento, pode acrescentar algo à identidade do sujeito, pode fazer com que este se sinta pertencente a um outro lugar, a um outro grupo, a uma outra linha de pensamento sem que, com isso, se apaguem as suas pertenças anteriores.

O texto literário é, por definição, um texto que congrega em si próprio uma multiplicidade de sentidos, é um texto que permite o contacto com o uso estético da língua e com diferentes formas de representação do mundo, fator enriquecedor da aprendizagem, nomeadamente de uma língua estrangeira, na medida em que veicula uma outra cultura, apresenta diferentes modos de pensar, diferentes histórias, diferentes personagens, diferentes mensagens. A leitura e análise do conteúdo de um texto literário podem levar o leitor a questionar-se acerca da sua própria visão do mundo e podem desafiá-lo a dialogar com outra cultura, com outras visões do mundo com as quais este, afetivamente, se pode identificar.

\section{O texto literário como veículo de culturas plurais: um estudo de dois casos}

Pensemos, por exemplo, em dois autores africanos: Mia Couto e Pepetela. Os textos de ambos apresentam, a nosso ver, dois elementos fundamentais para o desenvolvimento de uma pedagogia intercultural.

O primeiro elemento está relacionado com Mia Couto e com a sua capacidade de reinventar a língua. A reinvenção lexical, em Mia Couto, transporta consigo uma reinvenção semântica que coloca em diálogo dois universos diferentes: a mesma palavra pode ter diferentes significados, dependendo se é utilizada na língua portuguesa falada em Portugal ou na língua portuguesa de Moçambique. Mia Couto culturaliza a língua, atribuindo novas semânticas às palavras, cria a língua recriando-a. Nesse sentido, a leitura dos seus textos pode promover o 
diálogo intercultural, já que a palavra criada põe em relação o eu, conhecido, com o outro, desconhecido.

O segundo elemento, que encontro em Pepetela, é o diálogo com o outro, o contacto com a diferença como forma de pensar e refletir acerca da nossa própria identidade. Pepetela dá voz ao outro, dando a conhecer a sua visão do mundo e, ao dar-lhe a palavra, pode conduzir o leitor a refletir e a questionar-se sobre si próprio, a partir desse contacto com o outro. Assiste-se a uma crítica ao eu a partir da sua relação com o outro, o que pode dar origem a um frutífero diálogo intercultural.

Para concretizar estas reflexões, consideremos um conto de cada um dos autores: "Raízes" de Mia Couto e "Estranhos Pássaros de Asas Abertas" de Pepetela. Ambos podem ser didatizados no contexto de uma pedagogia intercultural.

Em "Raízes", por exemplo, a fim de estimular o desenvolvimento da consciência intercultural do aprendente de PLNM, seria interessante levá-lo a compreender a relação que o povo moçambicano tem à terra, imagem central do conto, presente desde logo no incipit: o homem tinha criado raízes à terra e esta ligação é de tal modo forte que ele sangra se o tentarem separar dela. Neste sentido, o aprendente pode ser levado a questionar quais serão os eventuais sentidos deste enraizamento indestrutível:

- Terá uma conotação negativa, revelando, por exemplo, inflexibilidade de pensamento, incapacidade de se desenraizar da terra mãe?

- Ou, pelo contrário, uma conotação positiva, transmitindo que o homem se deita na terra porque a ela deseja estar ligado para sempre, sem que nada o consiga transplantar da sua cultura?

- Após esta reflexão, o aprendente pode ser conduzido a refletir sobre de que modo é que este conto se pode ligar à sua cultura materna, qual a relação que os seus têm com a terra, com o país, com a cultura? Que imagem, por exemplo, na sua cultura, poderia substituir uma cabeça enraizada à terra?

No conto "Estranhos Pássaros de Asas Abertas", para o aluno de PLM, seria interessante refletir no facto de, como mostra Pepetela, também para os povos africanos os portugueses eram seres estranhos, diferentes, o outro, interiorizando que os enaltecidos heróis portugueses invadiram um território já povoado, apoderando-se dele, impondo uma língua e uma cultura estranhas, sem considerar que aquele espaço já tinha os seus hábitos culturais e a sua própria língua. 
Na sequência desta ideia, seria também pertinente descodificar o duplo alcance da figura do gigante Adamastor: n'Os Lusíadas é o símbolo do outro, do diferente que assusta e atormenta, que só é vencido quando ousam perguntar: "Quem és tu?"; neste conto, o Adamastor é a figura associada aos portugueses que, na visão dos africanos, são os gigantes assustadores. Também eles invadiram um espaço, também eles provocavam medo e pavor, também nós, portugueses, somos o outro para os outros e, consequentemente, motivo de desconfiança e retraimento. Para além disso, seria igualmente interessante associar certos excertos do conto a determinados excertos d'Os Lusíadas e de compreender que a caracterização dos portugueses como seres "estranhos", com um "cheiro pestilento" e um "aspeto desgrenhado de bandidos" (Pepetela, 2008: 71), é muito semelhante, em termos linguísticos, à descrição que Camões faz de Adamastor, gigante assustador, de odor pestilento e cabelos desgrenhados.

Com as propostas de didatização de ambos os contos, "Raízes", de Mia Couto, e "Estranhos Pássaros de Asas Abertas", de Pepetela, procurámos demonstrar que é possível, através do texto literário em língua portuguesa, que o aluno / aprendente desenvolva a sua competência linguística, de leitura, de expressão oral e escrita, mas também a sua competência intercultural. Nesse sentido, integrar, no processo de ensino / aprendizagem de PLM ou PLNM, o texto literário em língua portuguesa, favorece o estabelecimento de um diálogo com o outro e, na nossa perspetiva, auxilia na formação do aluno / aprendente, procurando que este desenvolva a capacidade não só de reconhecer e compreender a diversidade, mas de se sentir parte integrante da mesma, composta por si e pelo outro e enriquecida pelo diálogo entre ambos.

Quer Pepetela quer Mia Couto transformam a língua portuguesa num veículo pluricultural, e apresentam, de modos distintos, a realidade sob um olhar e sob uma perspetiva diferentes, lançam pistas de interpretação do mundo consubstanciada, textualmente, numa recriação da língua portuguesa, terreno de várias identidades e culturas, uma língua "que fabrica mestiçagem e está em troca com o mundo" (Couto, 2001: 10), essa língua cuja dinâmica e plasticidade é, segundo Mia Couto, "um material preciso para quem trabalha na escrita" (idem, p. 12). 


\section{Considerações finais}

Estudar o texto literário em língua portuguesa é, sem dúvida, o primeiro passo para construir uma ponte de diálogo com o outro. O texto literário português, brasileiro, africano, escrito na mesma língua, permite a diluição da estranheza pelo que é diferente, já que o diferente, o outro, é abordado em relação com o igual, o eu, transformando-se sem semelhante. Se realidades culturais aparentemente tão distintas podem coexistir no mesmo espaço estético, podem também coexistir no mesmo indivíduo, completar a sua identidade e enriquecê-lo culturalmente. 


\section{Referências}

ABDALLAH-PRETCEIILE, Martine. Vers une pédagogie interculturelle. Paris: Anthropos, 1996.

BIZARRO, Rosa. (org.). Eu e o Outro. Estudos multidisciplinares sobre identidade(s), diversidade(s) e práticas interculturais. Porto: Areal Editores, 2007.

BORGES, Maria Teresa Machado. Ensinando a ler sem silabar. Campinas, SP: Papirus, 2001.

CARLO, Maddalena del. L'interculturel. Paris : CLE International, 1998.

COUNCIL OF EUROPE. Education pack - idea, resources, methods and activities for informal intercultural education with young people and adults. Hungary: Council of Europe, 2004.

COUTO, Mia. "Lusofonia - história ou conveniência", in: LITERATA: Revista do Centro de Estudos Portugueses Hélio Simões, no 2, Ilhéus-BA, UESC, 2000/2001, pp. 8-12.

COUTO, Mia. Contos do nascer da terra. Alfragide: Editorial Caminho, 2009.

ESTEVES, José Manuel. “O lugar do texto literário no ensino do Português como língua estrangeira". In: Actas do Seminário Internacional Português como L.E. Macau, Instituto Português do Oriente, 1991. pp. 139-147.

FARMHOUSE, Rosário. "Diversidade e diálogo intercultural”. In: CABECINHAS, R., CUNHA, L. (eds.). Comunicação intercultural. Perspectivas, dilemas e desafios. Porto: Campo das Letras Editores S.A. 2008. pp. 13-17.

GERMAIN, Claude. Évolution de l'enseignement des langues: 5000 ans d'histoire. Paris : CLE International, 1993.

MAALOUF, Amin. As identidades assassinas. Lisboa: DIFEL, 1998.

MATA, Inocência. "O ensino das literaturas de língua portuguesa: um tempo intercultural". In: MATA, I., GROSSO, M.J. (coord.). Pelas Oito Partidas da Língua Portuguesa. Universidade de Macau, Instituto Politécnico de Macau, Departamento de Língua e Cultura portuguesa, FLUL. 2007. pp. 398-376.

MATA, Inocência. "No fluxo da resistência: a literatura, (ainda) universo de reinvenção da diferença". Gragoatá, Niterói-RJ, no 27, Universidade Federal Fluminense, 2009. pp. 11-31.

PEPETELA. Contos de Morte. Lisboa: Nelson de Matos. 2008. 